Archived version from NCDOCKS Institutional Repository http://libres.uncg.edu/ir/asu/

\title{
Appalachỉan
}

B O O N E, N O R T H C A R O L I N A

\section{The Empty Bowls Project: Creating, Leading, and Sustaining a Social Enterprise}

Authors:

Stella E. Anderson, Betty S. Coffey \& Heather Dixon-Fowler

\begin{abstract}
Lisa and John never envisioned that a luncheon held 20 years ago at their local high school would grow into The Empty Bowls Project, an international grassroots effort to fight hunger. The premise is simple in that potters, educators, students, and others create handcrafted bowls and serve a simple meal of soup and bread. In exchange for cash donations, attendees take home the bowl to recall all the empty bowls in the world. Monies raised are donated to community-based organizations working toward food security. The founders subsequently formed the nonprofit Imagine Render and now are considering their succession and future direction.
\end{abstract}

Stella E. Anderson, Betty S. Coffey \& Heather Dixon-Fowler (2013) "The Empty Bowls Project: Creating, Leading, and Sustaining a Social Enterprise" Entrepreneurship Theory and Practice Version of Record available @ (DOI: 10.1111/etap.12034) 


\title{
The Empty Bowls Project: Creating, Leading, and Sustaining a Social Enterprise
}

\author{
Stella E. Anderson \\ Betty S. Coffey \\ Heather Dixon-Fowler
}

\begin{abstract}
Lisa and John never envisioned that a luncheon held 20 years ago at their local high school would grow into The Empty Bowls Project, an international grassroots effort to fight hunger. The premise is simple in that potters, educators, students, and others create handcrafted bowls and serve a simple meal of soup and bread. In exchange for cash donations, attendees take home the bowl to recall all the empty bowls in the world. Monies raised are donated to community-based organizations working toward food security. The founders subsequently formed the nonprofit Imagine Render and now are considering their succession and future direction.
\end{abstract}

"The idea is a simple concept for raising money to feed the hungry. A meal of soup and bread is served in handmade bowls . . . attendees keep their bowls as a reminder of all the empty bowls in the world."

_ John Hartom

W hat started serendipitously as a simple luncheon in 1990 has grown into a grassroots movement to help end hunger that now has a successful 20-year track record. The founders, Lisa Blackburn and John Hartom, ${ }^{1}$ were at the time both art teachers in Michigan. They never imagined the ways in which what came to be called The Empty Bowls Project would grow over these years and touch so many people in so many different ways. Lisa recalled that sometimes everything comes together and magic occurs. From John and Lisa's perspective, they deserve very little of the credit, believing instead that it is the shared genius of all the people involved that has made The Empty Bowls Project what it has become. Collectively, there are thousands of ceramics artists, educators, students, and others who have devoted enormous time and energy to local Empty Bowls activities.

Please send correspondence to: Stella E. Anderson, tel.: 828262 6229; e-mail: andersnse@appstate.edu, to Betty S. Coffey at coffeybs@appstate.edu, and to Heather Dixon-Fowler at dixonfowlerh@appstate.edu.

1. Lisa Blackburn and John Hartom, founders of Empty Bowls/Imagine Render, provided information for case development and approved this case for the purpose of teaching and class discussion. 
As Lisa has said,

The Empty Bowls Project started serendipitously. We imagined it would be a onetime-only luncheon at Bloomfield Hills Lahser High School, in suburban Detroit, where John was teaching ceramics. After talking with the service-learning coordinator, who indicated that the district was running short of money for the annual food drive, John offered his students' help. Over dinner that night we considered options. We decided to challenge the students to make enough bowls to serve a soup luncheon to the school staff in exchange for their donations of money for the food drive. (Blackburn \& Hartom, 2011, p. 20)

These students enthusiastically accepted the challenge and the staff members responded in kind. This was the first of many subsequent events that became known as Empty Bowls events. At the conclusion of that first luncheon, staff members were surprised when they were asked to keep their bowls as a reminder of all the empty bowls in the world. Everyone in attendance was moved. John and Lisa knew they had just witnessed something special.

What motivated John and Lisa? What transpired that day inspired John and Lisa to consider taking this initial idea to replicate and extend the concept. Nothing in either John or Lisa's background or family experience directly connected them to the problems of hunger and food insecurity. A strong commitment to social justice issues was, in part, what motivated them to pursue careers as educators, and that same commitment to social justice motivated them to do something when it seemed that John's school would not meet a relatively modest fund-raising goal to support a local food drive. John and Lisa also believed in the importance of educating their students and other members of the school community about hunger and food insecurity that existed in their own local community. These concerns served as the impetus for John's challenge to his students to seize the opportunity to address an unmet need. John and Lisa realized that there were unmet community needs, and with the success of that initial luncheon, this type of an event could be an effective means for educating the community and addressing some of those needs.

With the success of that initial luncheon, John and Lisa were motivated to launch what became a national project. In the spring of 1991, they challenged potters and educators across the United States to raise \$1 million by October 16-World Food Day. Looking back they realize that was an extremely ambitious goal. "We were naïve, energetic, not knowing better or not knowing that we couldn't." In relatively short order the project began to take on a life of its own. As other communities held an initial Empty Bowls event, people wrote to John and Lisa about their first year's total funds raised and their goal for the next year's event. It never occurred to Lisa and John at the time that this would become an annual event and sustained effort over many years. So while that initial goal for World Food Day was not met in the first year, the goal was met many times over in the course of the early years. Reflecting on the growth and evolution of The Empty Bowls Project, Lisa says, "We envisioned first a school project, then a national one; now Empty Bowls events have taken place in at least fifteen countries and raised many millions of dollars."

In the early years, John and Lisa worked to tell the Empty Bowls story and motivate others to get involved in several different ways. In that first year, John and Lisa's connections were with professional associations of art educators and ceramic artists. They were sharing the idea through their network. In 1991 John spoke in Tempe, Arizona, at the National Council on Education for the Ceramic Arts (NCECA). This was their "grassroots" effort to tell the story and promote the concept in the hope that educators would be inspired to initiate an Empty Bowls event in their own community. As John recalls, "All the doors seemed to open in that first year." For example, the superintendent and deputy 
superintendent of schools in Bloomfield Hills, Michigan, where John was teaching when the project began, W. Robert (Bob) Docking and Gary Doyle, were supportive. Both believed in the project. Bob personally penned a letter that went to 500 statewide schools touting the success of the initial Empty Bowls event and encouraging the adoption of the project.

As the events began to spread, John and Lisa could generally trace where someone heard about The Empty Bowls Project and how that led to an event held in a given community. For instance, in 1997 John and Lisa spoke at the National Youth Leadership Council's National Service-Learning Conference in Detroit, Michigan. Over 1,000 conference participants were invited to attend an Empty Bowls luncheon. Participation in this event was a powerful motivating force that led Alice Del Vecchio to host an Empty Bowls event at Slippery Rock University. Students and faculty at Slippery Rock University have marked their 15th anniversary Empty Bowls event (Del Vecchio, 2010).

Needless to say Lisa and John can no longer trace exactly how the origin of the concept has spread, especially as it relates to the spread of Empty Bowls events outside the United States. A simple Google search turned up Empty Bowls events in at least 14 other countries, with neither Lisa nor John having any idea of the connections that led to these various events. John and Lisa described the phenomenon as "going viral" before the advent of the Internet.

\section{The Empty Bowls Concept}

How did this happen? What made this work? From Lisa and John's perspective, the growth and success of the project probably can be attributed to several factors. For one, the chosen name-Empty Bowls - is a metaphor that virtually everyone understands. Also, as John repeatedly points out, "It was important that we gave the idea away." They mean this literally, as they view themselves as "owning" the idea only for that one evening in 1990 when the initial idea for that first luncheon emerged. From that point on, the students, organizers, and communities took ownership, making the event their own by tailoring it to meet specific community needs.

Another factor in the success is the development of local ownership in carrying out an Empty Bowls event. John and Lisa invested countless hours in pitching the idea and helping local organizers get started in planning and organizing an Empty Bowls event. With that initial advice and support, local organizers were then entirely responsible for their own Empty Bowls event, designing it around the resources and needs of their local communities. Real ownership developed as well as the opportunity for individual creative input. Organizers found the resources to make the event happen within their own community. For example, local art teachers and potters created the bowls and local restaurants and bakeries provided the food. Organizers also select a local venue to host the event. Through the efforts of the local organizers and partners in the community, the project becomes in the end a real community-based event.

The simplicity of the idea likely contributed to the growth and success of Empty Bowls events. The basic premise is really quite simple - all that is asked of anyone wanting to organize such an event is that (1) the event is called Empty Bowls so that the idea continues to spread, (2) an educational component is included to raise awareness, and (3) all of the money raised is donated to an organization helping to feed people in need (http://www.emptybowls.net). As John says, "Many people may feel that alleviating hunger is too big or complex to even make a dent in solving or addressing individually. Empty Bowls provides something that anybody can do. Everybody has something to share 
and contribute to making an Empty Bowls event successful and to do so is to have a clear and significant impact in the local community."

Also, Lisa and John strongly believe that the inclusion of an educational component in an Empty Bowls event is fundamental for success. People learn about the scope of hunger and the issues behind hunger in their own community. One common recommendation for "what works" for local events is to ask a representative from the local agency receiving the donation to speak at the Empty Bowls event. This person can help to frame the hunger and food insecurity issue in the community. John and Lisa have received feedback from local organizers affirming the value of the educational component for raising awareness and engaging the community in helping to address the issue. The essence of the Empty Bowls concept is described as:

Our major project is The Empty Bowls Project, an international grassroots effort to raise both money and awareness in the fight to end hunger. This project represents what we do best - develop creative, exciting, and powerful models that are replicable and scalable by others wishing to work for social justice. ${ }^{2}$

\section{The Power of a Network}

John and Lisa, as art educators, had strong connections to bring together the social capital of educators, students, potters, and community members. This often meant bringing together people who did not know each other and had not previously worked together toward a common purpose. As educators they sought to involve as many schools and other educators in Empty Bowls as possible. For many educators, there is an inherent appeal to a project like Empty Bowls in that students learn a great deal through a service learning project in their community. Educators generally identify with the idea that through engagement in service learning projects, students are exposed to different views, gain direct experiences in helping others, and become educated about their community's needs. As Lisa describes, most educators can relate to the idea that "as an educator you plant a seed and oftentimes you just never really know the full extent of the impact."

From the standpoint of many educators and school administrators, The Empty Bowls Project had the capacity to become a part of the school's overall curriculum. In one example, in the elementary school in which Lisa taught art and first organized an Empty Bowls event, the school decided to start a garden and have the children help raise vegetables for making the soup served at the event. On the day of the event, the children helped the adults to cook the soup and bake the bread, and the older students presented a song written by a staff member. To this day, Lisa and John get an annual report from this elementary school that has celebrated a 20th anniversary Empty Bowls event. In another example at Slippery Rock University, preparation for an annual Empty Bowls event has involved faculty and students working together across multiple programs of study (i.e., AmeriCorps, sustainable organic systems, art, dance, music, and public relations).

In addition to tapping into a network of educators, John and Lisa simultaneously networked with potters and ceramic artists. They found the potter communities eager to support The Empty Bowls Project. In reflecting on this support, Lisa commented, "Potters like to see their pots in service. Potters have the best potlucks! And for many potters, there 
is an inherent connection between food (and feeding) and their pots." So through donations and participation in Empty Bowls events and working with ceramic arts educators, potters truly get to put their pots in service.

Through the years John and Lisa have maintained and extended their ties with both educator and artist networks. They have been relentless in championing grassroots efforts to fight hunger. They have continued this effort by speaking at annual national conferences, talking with people who call or e-mail with inquiries, engaging with community groups and agencies, writing articles, and doing interviews. They have been engaged in these activities consistently for more than 20 years. John and Lisa see a continuing need to present to key audiences, most notably the NCECA. With 5,000 7,000 ceramic arts educators and students meeting annually, John believes the story needs to continue to be shared with the NCECA because "this very group has in a large way been responsible for Empty Bowls working."

\section{Evolving Roles}

From the inception of the pilot Empty Bowls event, Lisa and John partnered in nurturing Empty Bowls. That first year was quite challenging, to say the least. Lisa and John were devoted to their careers as full-time teachers. With the success of the pilot event they then became committed to doing everything they could to turn Empty Bowls into a national project. By this point in time, Lisa and John were married, had full-time teaching positions, and devoted all of their remaining time to building The Empty Bowls Project. "John and I worked all the time." John and Lisa did everything. They both pitched the idea, planned and organized suggestions for how to get started, spoke at annual conferences, talked with people who called or e-mailed with inquiries, engaged with community groups and agencies, wrote articles, did interviews, and anything else to advance the cause. For a number of years, they did all of these activities with no separation of roles. The only differentiation of roles was based on who was the least overwhelmed at any point in time.

Only with time did Lisa and John's respective roles evolve and become more defined. When John retired from teaching, they reevaluated how they were spending time with Empty Bowls. John became the primary point person and in many ways the "face" for the endeavor by regularly speaking at key annual conferences and maintaining ties with potters and educators. Lisa took on the behind-the-scenes operational work. She worked with a web designer and developed the content for the project's website. ${ }^{3}$ The Empty Bowls archives have been a big responsibility for Lisa, as she felt strongly that these materials were central to what it meant to be "keepers of the Empty Bowls story."

\section{Forming a 501(c)(3) Nonprofit Organization}

Given the growth of Empty Bowls events, it soon became evident that an umbrella organization was needed to support and administer The Empty Bowls Project. John and Lisa were advised to file for 501(c)(3) nonprofit organization status. This form of a nonprofit organization would allow them to organize and operate with the ability to receive philanthropic dollars including private and corporate donations and grants from a foundation or government. These donations are tax exempt for the organization and 
potentially tax deductible for donors. In order to carry this designation, a nonprofit must be both organized and operated solely for charitable purpose(s) (http://www.irs.gov/ charities). A 501(c)(3) organization must adhere to annual government reporting requirements, often requiring the expertise of an accountant and an attorney. John and Lisa were determined that they would not be paid a salary even though IRS regulations for a 501(c)(3) allow for reasonable salaries for a manager or an administrator. Also, to support the operation and oversight of Imagine Render, John and Lisa formed a board of directors, with seven other individuals willing to serve on a voluntary basis. These volunteers were instrumental from very early on in supporting The Empty Bowls Project.

The nonprofit organization was named Imagine Render in recognition of the importance of both having a good idea (i.e., to imagine) and taking needed action (i.e., to render). The stated mission of Imagine Render is "to create positive and lasting social change through the arts, education, and projects that build community." Currently there is a small operating budget funded from individual, business, and foundation donations, and Imagine Render has remained an all-volunteer organization. Neither John nor Lisa earn a salary because they have been adamant that funds raised from Empty Bowls events will go directly to local community organizations addressing hunger needs. Thus, these funds are not used to support the work or administration of Imagine Render. Imagine Render's small operating budget primarily supports John in attending and speaking at annual conferences to promote The Empty Bowls Project.

As mentioned, the funds supporting Imagine Render have come primarily from individuals and small businesses. Imagine Render has benefited from a small grant from a foundation to cover the expenses of contracting with an archivist, who organized and preserved the many boxes of materials John and Lisa had received over the years from community organizers of Empty Bowls events. Early on, one of the board members advised John and Lisa to keep everything that described the events to tell the story of Empty Bowls. They consider that to be very good advice and literally have done just that. Doing so has resulted in boxes upon boxes of materials that local organizers have sent through the years. As Lisa stated, "The hundreds of anecdotes, stories, photographs, press clippings and keepsake bowls collectively tell the story of The Empty Bowls Project."

The nonprofit Imagine Render has assisted with other volunteer food-related projects beyond Empty Bowls. For example, Lisa and John worked with Oxfam America to deliver a child's bowl and a plea to end hunger to the office of every member of Congress. They helped Habitat for Humanity in Pontiac, Michigan, to build, install, and plant vegetable gardens at four new houses, leaving behind tools and instructions with each family. They helped to organize and co-host agriculture and extended-season gardening workshops. Additionally, they have led community mural-making activities on several occasions. Imagine Render ran art workshops for several years, all focused on developing creative thinking skills. Most recently, Imagine Render affiliated with the initial work on the development of a community garden to yield food that is donated to a local soup kitchen in Yancey County, North Carolina. Dig In Yancey! Community Garden ${ }^{5}$ now has its own 501(c)(3) status, benefiting local hunger relief agencies and hunger education efforts. 


\section{Assessing Social Impact and Reach}

In terms of assessing the impact of Empty Bowls and Imagine Render, initially John and Lisa had as their first-year goal to raise $\$ 1$ million for organizations addressing food insecurity. At the inception of the idea, Lisa and John had not envisioned anything beyond that initial goal. Now as Lisa and John look back on The Empty Bowls Project and Imagine Render, they have a different perspective on defining and measuring the social impact and reach of their efforts. As John says, "We stopped trying to keep track of the total amount of money raised through Empty Bowls events about eighteen years ago. After the first two years we had information that over $\$ 2$ million had been raised in local communities."

Lisa and John continue to receive some feedback about the monies raised and donated to local organizations fighting hunger from Empty Bowls events. However, they likely will never know of many, perhaps even most, of the events that take place in a given year. From that first year and continuing to this day, an organizer response form has been included in every information packet that John and Lisa send in response to Empty Bowls inquiries. Sometimes event organizers send feedback years after an event has been held. Lisa and John were surprised to learn from an organizer of Empty Bowls events in Flint, Michigan, that 16 successive annual events have been held with a total of $\$ 60,000$ raised for their community. John and Lisa are aware of other communities holding Empty Bowls events for 10 or 15 consecutive years running, often with accounts of substantial increases in funds raised from one year to the next. In a recent example, Empty Bowls luncheons held in February 2010 (on the same day) in Dallas and Fort Worth raised over $\$ 330,000$. That was enough for two local food banks to provide a million meals. Now, as technology has advanced, John says that he and Lisa "get daily Google alerts for Empty Bowls events" as another means to estimate the number and reach of events being held in communities around the world. Of course, these accounts represent only a subset of the total number of Empty Bowls events that have been held over the last 20 years. Inferring from direct feedback about local Empty Bowls events that have been held, it is estimated that several million dollars have been raised and donated to local organizations fighting hunger.

As another indicator of the impact and reach of Empty Bowls, one of the Imagine Render board members conducted a study of Feeding America member food banks to determine the extent to which the food banks were involved with and impacted by Empty Bowls. In surveying over 200 food banks in the United States, it was determined that nearly half were involved in some way with Empty Bowls, with many holding their own annual Empty Bowls event. For John and Lisa "astonishment" is the one word that seemed to capture the impact of this finding. Each of these major food banks generally supplies food to hundreds of local agencies in several counties in a region. John has explained, "For Empty Bowls events to directly benefit these major food banks means that Empty Bowls ends up supporting a wide array of agencies working on a local level to directly meet community food needs."

The assumption is that by raising the awareness about hunger and its causes, people will be better able to address hunger needs in their own communities. Each Empty Bowls event has an educational component to raise awareness about food insecurity. Imagine Render reaches many professionals, including lawyers, accountants, and graphic artists, just to name a few, who have donated their services pro bono to assist in supporting Empty Bowls and Imagine Render. For instance, when John and Lisa wanted to set up "throwing days" for producing bowls for Empty Bowls events, they got "remarkable support in terms of donated materials and expertise for building a kiln." These examples are illustrative of 
the commitment of volunteers whose time and donations help to raise the awareness of food insecurity.

While the growing number of Empty Bowls events and the amount of money raised in many ways demonstrate success, all of that does not change the fact that people are hungry and food insecurity exists in every community. John and Lisa are cognizant that Empty Bowls cannot solve the issue of hunger, yet they believe "The Empty Bowls project can bring awareness and bring people together to work in communities to help address hunger issues." John and Lisa vividly recall celebrating the impact of Empty Bowls at the 10 th anniversary and being hopeful that "surely there would not be a 20th anniversary, because surely there will not be a need to do this anymore." Nonetheless, they know that hunger remains widespread today with a growing number of people dealing with food insecurity. John and Lisa anticipate that The Empty Bowls Project and Imagine Render will continue to have a positive social impact on hunger through raising money and awareness in local communities.

\section{Looking Forward, Planning for the Future}

John, Lisa, and the board members know that there are significant challenges and opportunities for Imagine Render and Empty Bowls in the future. They are thinking about the near term as well as the longer-term commitments that would be necessary for The Empty Bowls Project and Imagine Render. As they think about efforts of The Empty Bowls Project over the last 20 years and consider the potential future impact, they know that local Empty Bowls events have provided monies for food banks and raised awareness of food insecurity in local communities. John describes that "in some ways an Empty Bowls event now has a life of its own, in that the concept has spread throughout the United States and to other countries."

While The Empty Bowls Project is well established, John and Lisa wonder about other Imagine Render initiatives once they step back from their current responsibilities. John and Lisa know that they and their board need to plan for an eventual transition in leadership. For instance, for sustaining Imagine Render, who would serve in the leadership role? Regarding other initiatives of Imagine Render, should they identify a volunteer or consider the possibility of hiring a director and staff to assume the day-today operational and communication responsibilities? They would never want funds raised from Empty Bowls events to be diverted from the purpose of directly supporting local hunger relief organizations. If they were to have paid staff for Imagine Render, alternative sources of funding would need to be identified and secured to cover administrative and overhead expenses. As they contemplate the next few years, they are interested in making careful plans about sustaining The Empty Bowls Project and Imagine Render into the future.

\section{REFERENCES}

Blackburn, L. \& Hartom, J. (2011). Empty bowls at twenty. Studio Potter, 39(1), 18-22.

Del Vecchio, A. (2010). Empty bowls, full hearts. Views \& Voices, November, 12-18. 
Stella E. Anderson is a professor at the Department of Management, Appalachian State University, ASU Box 32089, Boone, NC 28608.

Betty S. Coffey is a professor at the Department of Management, Appalachian State University, ASU Box 32089, Boone, NC 28608.

Heather Dixon-Fowler is an assistant professor at the Department of Management, Appalachian State University, ASU Box 32089, Boone, NC 28608.

The authors would like to acknowledge John Hartom and Lisa Blackburn, founders of Empty Bowls/Imagine Render. John and Lisa approved this case study in October 2011 and provided valuable information for the case to be developed for the purpose of teaching and class discussion.

\section{Note to Instructors}

\section{Introduction}

Empty Bowls/Imagine Render is a nonprofit social enterprise founded as a community grassroots effort with the purpose to fight hunger in local communities. After 20 years of growth and success in spreading the concept nationally and internationally, the founders must proactively consider questions about the future direction of the nonprofit organization and their changing leadership role. This case provides an opportunity for students to learn about the inception, evolution, and challenges of sustaining a nonprofit social enterprise. The case describes numerous decisions that the founders have faced as their roles and the organization have evolved over more than 20 years. Students can examine the mission, growth, and evolution of a social enterprise, the role of the founders, and the challenges and opportunities for the future of the endeavor.

\section{Key Issues and Discussion Points}

Essentially, the case provides a real story about a social enterprise from its inception to the present, the founders and their role in the organization, their novel solution to help address a social problem in local communities, and the growth of the enterprise. Students can apply theoretical concepts and frameworks from the social entrepreneurship literature to examine what defines a social enterprise and a social entrepreneur. Among the points emphasized in the case, the student can consider the motivations and passion of an individual to create a social enterprise. Students will see the various stages involved in the process of building a social enterprise, from opportunity recognition to concept development to venture growth and goal attainment.

Key issues and discussion points in the case include the following:

- Evaluating a social enterprise's mission

- Applying a process model for understanding a social enterprise's creation and development

- Examining the benefits and requirements associated with a 501(c)(3) designation

- Analyzing the resources, unique capabilities, and funding necessary to create value and fulfill a social mission

- Formulating recommendations for sustaining a social enterprise 


\section{Potential Audience and Uses}

This case would be relevant in a social entrepreneurship course or module of an entrepreneurship course at the upper-division undergraduate or graduate level. Also, the case could be used in a strategy or leadership course to provide the basis for discussion on strategic planning and/or leadership succession. The suggested positioning of this case is at the beginning of the module that considers social entrepreneurship. The case could be assigned to stimulate discussion and thinking about the definition of a social enterprise, the creation of ideas for a novel solution to a social cause, and realization of the passion of the founders. The case provides a real story about founders who created a social enterprise that is dedicated to bringing awareness and raising funds to address hunger in local communities. The case is written to allow students to put themselves in a real situation. Students with little experience could relate to the idea of pursuing a novel idea to address a social issue in their own community. Also, students may have participated in and/or organized an Empty Bowls event in their local community. The case could be used as a basis for discussion on defining and distinguishing social enterprises, understanding what motivates a social entrepreneur, fundamental concepts of mission, and the steps in the process of creating, developing, and sustaining a social enterprise.

\section{Suggested Teaching Approach}

Several possible approaches could be used to introduce the case and highlight the story of the social enterprise and its founders. The case would be suitable as the basis for class discussion as well as an individual or group assignment. Discussion questions could be provided to the students as a basis for their analyses. A number of individual or group in-class activities could be utilized effectively in conjunction with discussion of the case.

\section{Outside or Supplementary Readings}

Bluestein, A. (2011). Start a company. Change the world. Inc., 33(4), 71-80.

The article features a practical guide to social entrepreneurship. Also, see http://www. inc.com/social-entrepreneurs-2011 for a start-up guide for would-be social entrepreneurs and video interviews with founders who are featured in the magazine article.

Dees, J.G. (1998). The meaning of "social entrepreneurship." Center for the Advancement of Social Entrepreneurship, The Fuqua School of Business, Duke University, Durham, NC. Available at http://www.caseatduke.org/documents/dees_sedef.pdf, accessed 19 March 2013.

This article and other resources on social entrepreneurship are found at the CASE website at http://www.caseatduke.org.

Hays, J. (2011). How to make an impact on hunger. CNN. November 28, story and video. Available at http://www.cnn.com/2011/10/12/world/iyw-how-to-help-hunger/index.html, accessed 19 March 2013.

The video and story include an interview with John Hartom (founder) about The Empty Bowls Project. Hartom discusses how the ceramic arts can be employed in the fight against hunger in local communities. 


\section{Other Notes}

Instructors could complement the use of the case with a service-learning component where students organize and hold an Empty Bowls event at their university and/or attend an Empty Bowls event in their local community. Also, after covering the case, students might identify other unique ways to address the problems of hunger in their local communities. Students could search the Internet or newspaper accounts to identify various communities and countries where Empty Bowls events have been held and examine the ways that local communities have coordinated and supported the events.

\section{Role of the Authors}

The authors (management professors with interests in social entrepreneurship and service learning) were inspired to interview founders Lisa Blackburn and John Hartom to learn more about the inception and evolution of The Empty Bowls Project and grassroots effort to fight hunger and food insecurity. The authors conducted in-person interviews, researched public records on the events, attended Empty Bowls events, and discussed with John and Lisa the archives and letters of thanks that they have received during the 20 years they have campaigned for the cause of hunger. It has been a pleasure to speak with John and Lisa a number of times to learn more about their commitment to The Empty Bowls Project and Imagine Render. 